\title{
Gli1 regulates stemness characteristics in gastric adenocarcinoma
}

Wenbo Qi ${ }^{1,2}$, Zhaoting Yang ${ }^{1,3}$, Ying Feng ${ }^{1,3}$, Haoyue Li, ${ }^{1,3}$, Nan Che $e^{1,3}$, Lan Liu $4^{*}$ and Yanhua Xuan ${ }^{1,3^{*}}$

\begin{abstract}
Background: Glioma-associated oncogene homolog 1 (Gli1), affects the progression and the stemness characteristics of malignant carcinoma. The aim of the present study was to identify the relation between Gliomaassociated oncogene homolog 1 (Gli1) and stemness and determine its clinical significance in gastric adenocarcinoma (GA). We investigated Gli1 expression and its correlation with other stemness-associated proteins in 169 GA samples and 5 GA cell lines.

Methods: To elucidate the role of Gli1 in the clinicopathological significance and stemness of GA, tissues samples from 169 GA patients were collected for immunohistochemistry (IHC). Additionally, MKN74, MKN28, NCI-N87, SNU638, AGS cells were collected for western blotting, MKN28 cells were collected for spheroid formation assay.

Results: Results showed that Gli1 expression was closely related to tumor grade, primary tumor (pT) stage, distant metastasis, clinical stage, gross type, microvessel density, and shorter overall survival (OS). Cox regression analysis verified that Gli1 was an independent prognostic factor for OS. Furthermore, Gli1 expression correlated with the expression of stemness-related genes, CD44, LSD1, and Sox9. Gli1 inhibitor GANT61 significantly decreased the expression of CD44 and LSD1, and spheroid formation ability of the MKN28 cells.
\end{abstract}

Conclusions: In conclusion, Gli1 may be a poor prognostic indicator and a potential cancer stemness-related protein in GA.

Keywords: Glioma-associated oncogene homolog 1, Gastric adenocarcinoma, Cancer stemness, Prognosis

\section{Background}

As one of the common digestive tract tumors, gastric adenocarcinoma (GA) poses a serious threat to the health of patients across the world, especially in Asian countries. It was found that the 5-year survival rate for patients with early stage GA is approximately $90 \%$, but it decreases to $16.6 \%$ for patients with advanced GA [1]. Although there are many treatments for advanced GA, the overall survival (OS) is still poor. Therefore, it is necessary to improve the current therapeutic modalities

\footnotetext{
* Correspondence: lliu@ybu.edu.cn; xuanyh1@ybu.edu.cn

${ }^{4}$ Department of Pathology, Affiliated Hospital of Yanbian University, Yanji, China

${ }^{1}$ Institute for Regenerative Medicine, Yanbian University College of Medicine, Yanji, China

Full list of author information is available at the end of the article
}

and to explore new biomarkers for predicting the progression of GA, thereby advancing in targeted therapies.

Cancer stem-like cells (CSCs) maintain the viability of the cancer cell population through self-renewal and infinite proliferation, and play an important role in survival, proliferation, metastasis, and tumor recurrence. CSCs are viewed as novel therapeutic targets due to their stemness potential [2]. Thus, understanding the molecular mechanisms of CSCs in GA initiation and progression may help elucidate the pathogenesis of GA.

The Hedgehog $(\mathrm{Hh})$ signaling pathway comprises the Hh ligand (SHh, IHh, and DHh); twelve-transmembrane protein receptor, Patched (Ptc); seven- transmembrane protein receptor, Smoothened (Smo); Glioma-associated oncogene (Gli) family of transcription factors; and downstream target genes. The PTC gene includes the two

(c) The Author(s). 2020 Open Access This article is licensed under a Creative Commons Attribution 4.0 International License, which permits use, sharing, adaptation, distribution and reproduction in any medium or format, as long as you give appropriate credit to the original author(s) and the source, provide a link to the Creative Commons licence, and indicate if changes were made. The images or other third party material in this article are included in the article's Creative Commons licence, unless indicated otherwise in a credit line to the material. If material is not included in the article's Creative Commons licence and your intended use is not permitted by statutory regulation or exceeds the permitted use, you will need to obtain permission directly from the copyright holder. To view a copy of this licence, visit http://creativecommons.org/licenses/by/4.0/ The Creative Commons Public Domain Dedication waiver (http://creativecommons.org/publicdomain/zero/1.0/) applies to the data made available in this article, unless otherwise stated in a credit line to the data. 
homologs, PTCH1 and PTCH2, and both gene products can bind to Hh ligands. In the absence of the Hh ligand, PTCH inhibits Smo activity. The presence of Hh ligand relieves this inhibition, allowing smo to activate the Gli family of transcription factors. Gli1 has been implicated in several human cancers, including a role in the progression of pancreatic cancer [3] and an association with poor prognosis in glioblastoma [4], pancreatic cancer [5], and breast cancer [6]. Gli1 expression correlates with stemness in breast and lung cancers and is essential in the cellular proliferation and growth of these tumors [7, 8]. Although Gli1 expression has been studied in many human cancers, its role as a prognostic indicator and its functional significance in determining the stemness of GA cells warrants further investigation.

In this study, we investigated the clinicopathological value of Gli1 and evaluated the correlation between Gli1 and stemness in GA.

\section{Materials and methods Tissues}

One hundred sixty-nine cases GA tissue in paraffin section were gained from the Affiliated Hospital of Yanbian University and comply with agreements approved by the institutional review committee. The tissue samples were collected from 1995 to 2000. Preoperative chemotherapy or radiotherapy was not implemented. Clinical and pathological reports were reviewed for age, sex, tumor size, tumor grade, tumor location, primary tumor $(\mathrm{pT})$ stage, lymph node metastasis, distant metastasis, gross type and histological type.

\section{Cell lines}

MKN74, MKN28, NCI-N87, SNU638, and AGS, were bought from the ATCC and were maintained in 1640 contained with $10 \%$ fetal bovine serum (FBS, Life Technologies, Grand Island, NY), $100 \mathrm{mg} / \mathrm{ml}$ penicillin $\mathrm{G}$ and $50 \mathrm{mg} / \mathrm{ml}$ streptomycin (Life Technologies, Grand Island, NY) at $37^{\circ} \mathrm{C}$ in a humidified atmosphere containing $5 \% \mathrm{CO}_{2}$. MKN28 and MKN74 cells were treated with corresponding GANT61 (GAN, ENZO Lifesciences).

\section{Immunohistochemical (IHC) staining procedure}

After routinely dewaxing and hydration, sections proceed to be antigen repaired with TE buffer at $98^{\circ} \mathrm{C}$. Each section was blocked with $3 \% \mathrm{H}_{2} \mathrm{O}_{2}$. Each section was incubated with anti-Gli1 (Abcam), anti-CD44 (Abcam), anti-LSD1 (Sigma), anti-Sox2 (R\&D), antiSox9 (Abnova), anti-LGR5 (Abcam), in primary antibody dilution buffer for $1 \mathrm{~h}$ at ambient temperature (AT). Then anti-mouse/rabbit antibody were used to incubated with tissue samples for $30 \mathrm{~min}$ at AT. Lastly, chromogenic agent 3, 3'-diaminobenzidine (Dako) was used to stain tissue samples.
The double immunostaining procedure was executed in the same section, the first step was to use anti-Gli1 antibody staining with 3,3'-diaminobenzidine, the second step was to use anti-CD105 antibody (Abcam) staining with AEC.

Two pathologists (WB Qi \& YH Xuan) assessed the immunohistochemical results and the staining results were assessed according to previous study [9].

\section{Western blotting}

The tumor cells were lysed by using RIPA buffer with Phenyl methane sulfonyl fluoride (PMSF). The same amount of protein was separated with 10\% SDS-PAGE gel and then was transferred onto PVDF membranes (Biotech). Subsequently, 5\% skim milk (diluted in PBS) was used to blocked the PVDF membranes for $2 \mathrm{~h}$ at RT. And then the membranes were incubated with anti-Gli1 (Santa), anti-CD44 (Abcam), anti-LSD1 (ZSGB-BIO), anti-Sox9 (Abcam), anti- $\beta$-actin (Abcam). The next step is to incubate anti-rabbit/mouse for $2 \mathrm{~h}$. Detection was performed by the ECL kit.

\section{Immunofluorescence analysis}

MKN28 cells were planted and were cultured to 60$70 \%$ density. $4 \%$ polyformaldehyde was used to fix cells for $20 \mathrm{~min}$. And $0.5 \%$ Triton X-100 was used to permeabilize cells for 20 min. Next, 3\% BSA was used to block cells for $1 \mathrm{~h}$. Absorbent paper absorbs the sealing liquid and does not wash. Cells were incubated with anti-Gli1/LSD1, anti-Gli1/Sox 9 for $2 \mathrm{~h}$. The next day, cells were incubated with secondfluorescence antibodies (Invitrogen, A12380 and A11008) for $1 \mathrm{~h}$. Finally, DAPI was used to stain the nuclear. Fluorescence detection was performed with the Axiovert200II (Carl-Zeiss).

\section{Tumorsphere-forming assay}

MKN28 cells were maintained in serum-free DMEM medium (Invitrogen) with EGF (Pepro Tech), bFGF (Pepro Tech), B27 (GIBCO), heparin (Sigma), penicillin and streptomycin. Subsequently, cells were planted in low attachment culture dishes (Corning). After 1 week and 2 weeks, light microscopy was used to examine cell morphology.

\section{Statistical analysis}

SPSS 25.0 statistical software (NO. 1975-01566-C), Pearson's chi-square test and mean \pm standard deviation was used for the data analysis, and the results was evaluated by analysis of variance. The KaplanMeier method was used to identify the overall survival (OS) and were compared using the log-rank test. Univariate and multivariate analysis was used for the Cox proportional hazards model. The GraphPad 
Prism 7 software is used for statistics on the results of western blotting. $P$ value less than 0.05 was considered to have statistical significance.

\section{Results}

Association between the expression of Gli1 and clinical characteristics of GA

To understand if Gli1 is associated with GA progression, we investigated Gli1 expression in human GA by a Tissue Microarray (TMA) analysis. TMA analysis was performed for Gli1 expression by IHC staining in adjacent non-tumorous gastric epithelium and GA tissues. IHC staining revealed that Gli1 expression in GA (Fig. 1b-c) was higher than non-tumorous gastric epithelium (Fig. 1a). Gli1 significantly correlated with tumor grade $(P=0.001)$, pT stage $(P=0.029)$, clinical stage $(P=0.005)$, distant metastasis $(P=0.007)$, and gross type $(P=0.021)$ (Table 1$)$, not with age, sex, tumor location, tumor size, lymph node metastasis, histological type. Interestingly, our results find a correlation between Gli1 expression and $\mathrm{pT}$ stage and distant metastasis, but no correlation with tumor size or lymph node metastasis. These results are accordance with the data in GEPIA (Gene Expression Profiling Interactive Analysis) and TCGA (The Cancer Genome Atlas) that Gli1 expression was higher in clinical stage $(2 / 3 / 4)$ compared with clinical stage (1) $(P<0.001)$, and was not correlated with lymph node metastasis (Supplemental Figure).

The Kaplan-Meier survival analysis revealed that Gli1 expression in GA was associated with lower OS $(P<0.001$; Fig. 1d $)$. The univariate Cox regression analysis showed that tumor size, pT stage, lymph node metastasis, distant metastasis, and Gli1 expression (all $P<0.05$ ) were independent prognostic factors for poor OS. The multivariate Cox regression analysis revealed that $\mathrm{pT}$ stage, lymph node metastasis, distant metastasis, and Gli1 expression (all $P<0.05$ ) were independent prognostic predictors for OS (Table 2). These results demonstrated that Gli1 is a potential prognostic biomarker of GA.

Furthermore, double-staining results proved that CD105 expression (blood vessels) was around Gli1 expression (cancer cells) (Fig. 1e). Microvessel density (MVD) was significantly higher in Gli1(+) group $(55.51 \pm 36.34)$ than in Gli1(-) group $(36.86 \pm 30.85)$ $(P=0.003$; Fig. 1f). These results demonstrated that Gli1 may be likely to metastasize through the microangiogenesis and then promoting distant metastasis and finally promote tumor progression. This result further explained the potential reasons why there is an association between Gli1 and distant metastasis.
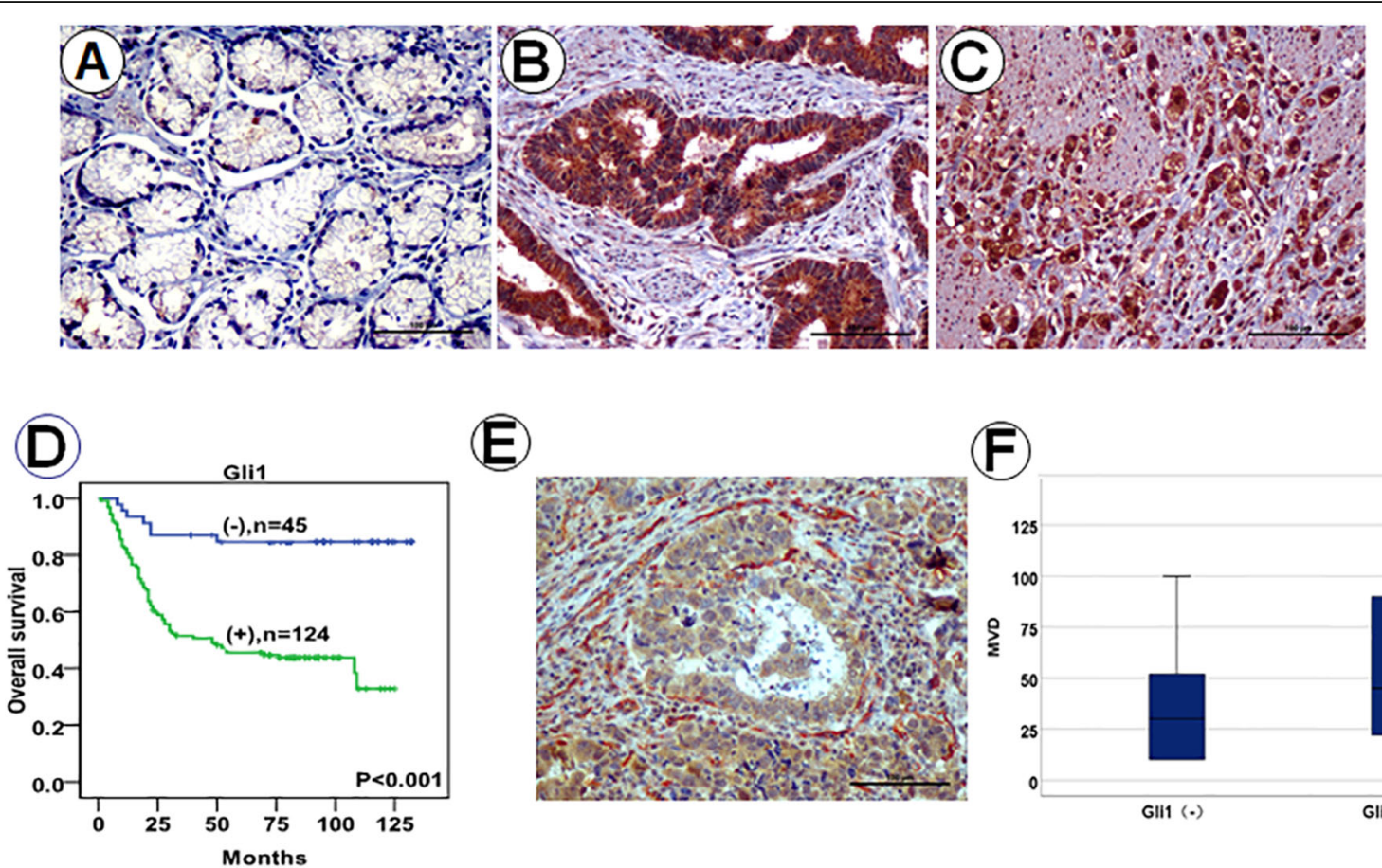

(F)

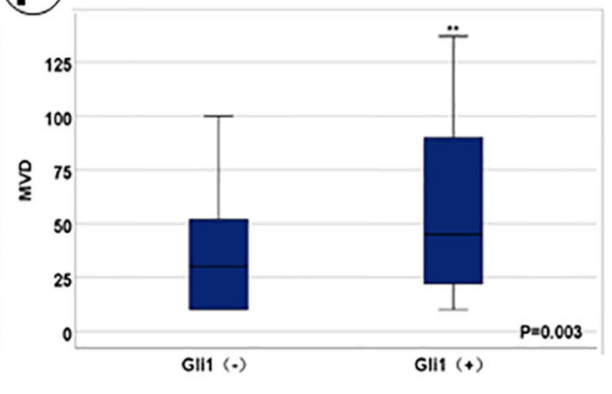

Fig. 1 Gli1 is associated with unfavorable clinicopathological parameters in GA. Immunohistochemical staining of Gli1 expression in normal gastric epithelium tissues (a), moderate differentiated GA (b), poor differentiated GA (c). The positive expression of Gli1 in GA was significantly associated with a shortened OS compared to the negative groups (d). Images of immunohistochemical double staining for Gli1/CD105 in GA tissues (Gli1: brown reaction product; CD105: red reaction product) (e). Expression of Gli1 in GA was significantly associated with increased microvessel density (MVD) (f) 
Table 1 Comparison of clinicopathologic characteristics according to the Gli1 expression in GA

\begin{tabular}{|c|c|c|c|c|c|c|}
\hline Variable & $\mathrm{N}$ & Gli1(-)n (\%) & Gli1(+)n (\%) & $x^{2}$ & $R$ & $P$ \\
\hline Age (years) & & & & 1.448 & 0.093 & 0.229 \\
\hline$<65$ & 109 & $32(29.4)$ & $77(70.6)$ & & & \\
\hline$\geq 65$ & 60 & $13(21.7)$ & $47(78.3)$ & & & \\
\hline Sex & & & & 1.347 & 0.089 & 0.246 \\
\hline Male & 106 & $25(23.6)$ & $81(76.4)$ & & & \\
\hline Female & 63 & $20(31.7)$ & $43(68.3)$ & & & \\
\hline Tumor size $(\mathrm{cm})$ & & & & 0.759 & 0.065 & 0.384 \\
\hline$<4.5$ & 63 & $19(30.2)$ & $44(69.8)$ & & & \\
\hline$\geq 4.5$ & 106 & $26(24.5)$ & $80(75.5)$ & & & \\
\hline Tumor grade & & & & 15.771 & 0.049 & $0.001^{*}$ \\
\hline Well & 31 & $14(45.2)$ & $17(54.8)$ & & & \\
\hline Moderate & 66 & $11(16.7)$ & $55(83.3)$ & & & \\
\hline Poor & 72 & $20(27.8)$ & $52(72.2)$ & & & \\
\hline Tumor location & & & & 1.943 & 0.024 & 0.584 \\
\hline Antrum & 93 & $23(24.7)$ & $70(75.2)$ & & & \\
\hline Cardia & 3 & $0(0)$ & $3(100.0)$ & & & \\
\hline Body & 63 & 20(31.7) & $43(68.3)$ & & & \\
\hline Mix & 10 & $2(20.0)$ & $8(80.0)$ & & & \\
\hline pT stage & & & & 9.034 & 0.218 & $0.029^{*}$ \\
\hline 1 & 35 & $16(45.7)$ & $19(54.3)$ & & & \\
\hline 2 & 38 & $11(28.9)$ & $27(71.1)$ & & & \\
\hline 3 & 92 & $17(18.5)$ & $75(81.5)$ & & & \\
\hline 4 & 4 & $1(25.0)$ & $3(75.0)$ & & & \\
\hline Lymph node metastasis & & & & 1.949 & 0.105 & 0.163 \\
\hline Negative & 144 & $41(28.5)$ & $103(71.5)$ & & & \\
\hline Positive & 25 & $4(16.0)$ & $21(84.0)$ & & & \\
\hline Distant metastasis & & & & 7.403 & 0.208 & $0.007^{*}$ \\
\hline Negative & 151 & $45(29.8)$ & $106(70.2)$ & & & \\
\hline Positive & 18 & $0(0)$ & $18(100.0)$ & & & \\
\hline Clinical stage & & & & 12.799 & 0.262 & $0.005^{*}$ \\
\hline 1 & 44 & $18(40.9)$ & $26(59.1)$ & & & \\
\hline 2 & 34 & $11(32.4)$ & $23(67.6)$ & & & \\
\hline 3 & 73 & $16(21.9)$ & $57(78.1)$ & & & \\
\hline 4 & 18 & $0(0)$ & $18(100.0)$ & & & \\
\hline Gross type & & & & 5.365 & 0.177 & $0.021^{*}$ \\
\hline Early gastric cancer & 37 & $16(43.2)$ & $21(56.8)$ & & & \\
\hline Advanced gastric cancer & 132 & $29(22.0)$ & $103(78.0)$ & & & \\
\hline Histological type & & & & 0.389 & 0.032 & 0.823 \\
\hline Intestinal & 91 & $26(28.6)$ & $65(71.4)$ & & & \\
\hline Diffuse & 70 & $17(24.3)$ & $53(75.7)$ & & & \\
\hline Mix & 8 & $2(25.0)$ & $6(75.0)$ & & & \\
\hline Survival & & & & 23.883 & 0.375 & $<0.001^{*}$ \\
\hline Die & 78 & $7(9.0)$ & $71(91.0)$ & & & \\
\hline Alive & 91 & $38(41.8)$ & $53(58.2)$ & & & \\
\hline
\end{tabular}

*Statistically significant findings

Correlation between Gli1 and stemness in GA

We have reported that Gli1 is associated with stemness in breast cancer and lung squamous cell carcinoma [9,
10]. To identify the role of Gli1 in cancer stemness of GA, we studied Gli1 and stemness-related protein expression in GA. The result showed that Gli1 related with 
cancer stemness proteins, CD44, LSD1, and Sox9 (all $P<0.05$ ) (Fig. 2a) (Table 3). Gli1, LSD1, Sox9 were primarily expressed in the nucleus of cancer cells; CD44 primarily located in the membranes of cancer cells. To further confirm above results, we investigated Gli1, CD44, LSD1, Sox9 expression in GA cells by western blotting. Gli1 expression in GA cells (MKN74, MKN28, NCI-N87, SNU638, AGS) were similar with stemnessrelated proteins (Fig. 2b). Furthermore, an immunofluorescence assay indicated that the Gli1-positive cell population were strongly identical with the LSD1 and Sox 9 positive cell population within the MKN28 cells (Fig. 2c).

To further understand the interaction between Gli1 and cancer stemness in GA cells, we blocked Gli1 expression using Gli1 inhibitor in MKN28 and MKN74 cells. Our studies showed that protein CD44, LSD1, Sox9 expression in MKN28 and MKN74 cells were significantly decreased after Gli1 was inhibited $(P<0.05$, Fig. 3a-b). Subsequently, tumorsphere-forming experiment was performed to investigate the ability of clonogenic potential of MKN28 cells. Notably, MKN28 cells dealed with GANT61 reduced clonogenic potential compared with cells treated with DMSO (control group)
(Fig. 3c). These results indicate a possibility that expression of Gli1 may enhances cancer cells to acquire stemness properties thereby promoting progression of GA.

\section{Discussion}

Gli1 promotes the progression of many types of cancers including, pancreatic and prostate cancer [10-12]. Our study showed that Gli1 is overexpressed in GA tissue samples, and its expression correlates with adverse clinicopathological parameters. This suggests a role for Gli1 in the initiation, progression, and metastasis of GA. In addition, Gli1 expression correlates with unfavorable prognosis of breast cancers [13-15]. Our survival analysis revealed similar poor prognosis correlated with Gli1 overexpression in GA. Angiogenesis is an important step in malignant tumor growth and progression [16]. Abnormally activated Hh/Gli1 pathway in gliomas promotes tumor microvessel formation [17], and Gli1 overexpression in esophageal tumors significantly correlates with increased microvessel density [18]. Similarly, Gli1 expression in our study was also associated with higher microvessel density, indicating that Gli1 may promote the progression of GA via angiogenesis.

Table 2 Univariate and multivariate analyses of prognostic variables for overall survival in GA patients using Cox proportional hazards regression

\begin{tabular}{|c|c|c|c|c|c|c|}
\hline \multirow[t]{2}{*}{ Characteristic } & \multicolumn{3}{|c|}{ Univariate analyses } & \multicolumn{3}{|c|}{ Multivariate analyses } \\
\hline & $\mathrm{HR}$ & $95 \% \mathrm{Cl}$ & $P$ & $\mathrm{HR}$ & $95 \% \mathrm{Cl}$ & $P$ \\
\hline Age (years) & & & 0.202 & & & 0.494 \\
\hline$<65$ & 1.00 & & - & 1.00 & & - \\
\hline$\geq 65$ & 1.326 & $0.859-2.044$ & & 1.178 & $0.737-1.882$ & \\
\hline Tumor size (cm) & & & $0.007^{*}$ & & & 0.888 \\
\hline$<4.5$ & 1.00 & & & 1.00 & & \\
\hline$\geq 4.5$ & 1.918 & $1.190-3.091$ & & 1.042 & $0.591-1.835$ & \\
\hline pT stage & & & $<0.001^{*}$ & & & $<0.001^{*}$ \\
\hline 1 & 1.00 & & & 1.00 & & \\
\hline 2 & 4.944 & $1.440-16.974$ & & 1.639 & $1.154-22.990$ & \\
\hline 3 & 12.358 & $3.875-39.412$ & & 2.352 & $2.472-44.689$ & \\
\hline 4 & 20.989 & $4.690-93.938$ & & 3.854 & $7.152-311.452$ & \\
\hline Lymph node metastasis & & & $<0.001^{*}$ & & & $<0.001^{*}$ \\
\hline Negative & 1.00 & & - & 1.00 & & - \\
\hline Positive & 5.610 & $3.446-9.133$ & & 3.272 & $1.908-5.613$ & \\
\hline Distant metastasis & & & $<0.001^{*}$ & & & $0.002^{*}$ \\
\hline Negative & 1.00 & & - & 1.00 & & - \\
\hline Positive & 5.050 & $2.952-8.640$ & & 2.528 & $1.416-4.513$ & \\
\hline Gli1 & & & $<0.001^{*}$ & & & $0.002^{*}$ \\
\hline Negative & 1.00 & & - & 1.00 & & - \\
\hline Positive & 5.245 & $2.401-11.458$ & & 3.572 & $1.573-8.112$ & \\
\hline
\end{tabular}

*Statistically significant findings 


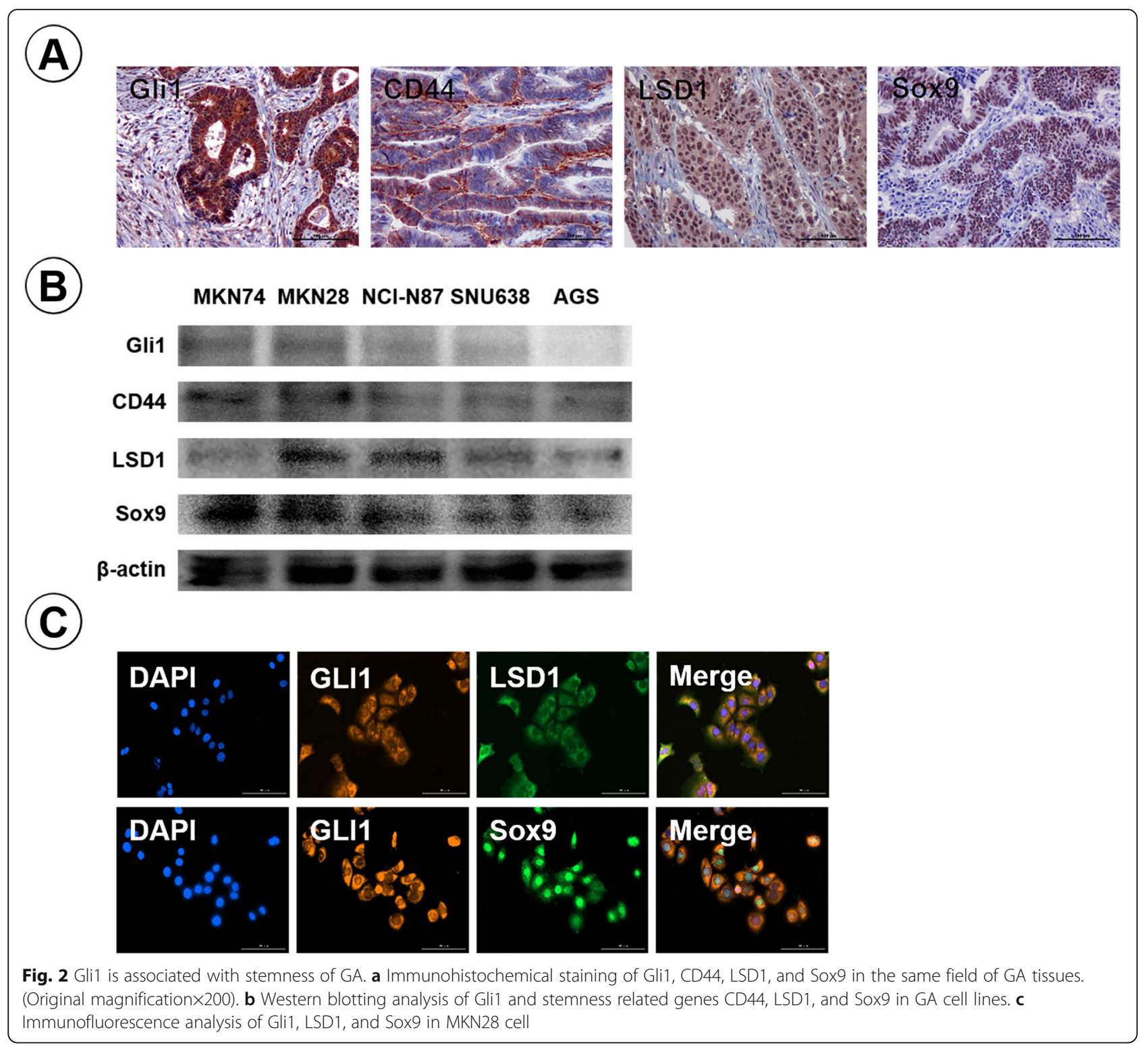

In human gliomas, the Hh/Gli1 pathway plays an important role in CSC self-renewal and tumorigenicity [19]. Gli1 expression also significantly correlates with stemness characteristics of esophageal carcinoma [18]. Moreover, some of stemness related proteins were used to identify the gastric CSC populations, such as CD44, CD133, LSD1, Sox9, LGR5 [20-25]. Evidence exists for the presence of cancer stem cells in colorectal cancer, with some phenotypes being CD44+/CD166+ enriched CSCs [26]. Our study demonstrated that Gli1 expression correlates with expression of cancer stemness-related proteins. Colocalization of Gli1 with cancer stemnessrelated proteins in GA tissue indicates that Gli1 may be an important stemness-related protein in GA. Furthermore, stemness-related protein expression in MKN28 and MKN74 cell lines and the ability of MKN28 cell lines to form spheroids were diminished after Gli1 inhibitor GANT61 was used. These factors prove that Gli1 regulates specific features of CSCs, such as self-renewal and proliferation. However, further investigation is necessary to elucidate the mechanism of Gli1 action in GA stem cells.

The SHh signaling pathway is a major regulator of tumorigenesis, tumor progression and therapeutic response. Downstream effectors of the SHh pathway include Smo and Gli family of zinc finger transcription factors. Both are regarded as important targets for cancer therapeutics. SMO inhibition prevents the downstream activation of Gli transcription factors, leading to suppression of those genes associated with cancer growth and progression. To date, SMO inhibitors include cyclopamine [27], LDE225 [28], and GDC-0449 
Table 3 Correlation of Gli1 expression with cancer stemness related proteins expression in GA

\begin{tabular}{|c|c|c|c|c|c|c|}
\hline Variable & $\mathrm{N}$ & Gli1(-) n(\%) & Gli1(+) n(\%) & $x^{2}$ & $R$ & $P$ \\
\hline CD44 & & & & 5.595 & 0.178 & $0.018^{*}$ \\
\hline Negative & 2 & $2(100.0)$ & $0(0)$ & & & \\
\hline Positive & 167 & $43(25.7)$ & $124(74.3)$ & & & \\
\hline LSD1 & & & & 17.866 & 0.318 & $<0.001^{*}$ \\
\hline Negative & 58 & $27(46.6)$ & $31(53.4)$ & & & \\
\hline Positive & 111 & 18(16.2) & $93(83.8)$ & & & \\
\hline Sox2 & & & & 3.057 & 0.132 & 0.080 \\
\hline Negative & 5 & $3(60.0)$ & $2(40.0)$ & & & \\
\hline Positive & 164 & $42(25.6)$ & $122(74.4)$ & & & \\
\hline Sox9 & & & & 12.748 & 0.271 & $<0.001^{*}$ \\
\hline Negative & 7 & $6(85.7)$ & $1(14.3)$ & & & \\
\hline Positive & 162 & $39(24.1)$ & 123(75.9) & & & \\
\hline LGR5 & & & & 1.869 & 0.105 & 0.172 \\
\hline Negative & 83 & $26(31.3)$ & $57(68.7)$ & & & \\
\hline Positive & 86 & $19(22.1)$ & $67(77.9)$ & & & \\
\hline
\end{tabular}

*Statistically significant findings

[29] were investigated in GC. Gli1 is an extremely important part of the Hh signaling pathway and can activate most of the Hh pathway target genes. Developing Gli-targeted approach has its merit because of the fact that Gli proteins can be activated by both SHh liganddependent and -independent mechanisms. Gli1 and Gli2 inhibitor include GANT 61 [30] and Arsenic Trioxide
[31] that have shown potent inhibition of Gli1 and Gli2 in many cancer cell lines, one of these is GC cells. Currently, many preclinical studies and clinical trials are being conducted to evaluate the efficacy of this exciting class of targeted therapy in a variety of cancers. We expect these inhibitors to be used clinically to help GC patients with targeted therapies.

Generally, targeting cancer cell stemness-associated genes may be an effective therapeutic strategy to overcome tumor relapse and chemoresistance. In this study, Gli1 proved to be a molecular marker for cancer stemness and a prognostic indicator of GA. We speculate that jointly targeting Gli1 and other cancer stemness biomarkers will provide a novel vision to treat GA.

\section{Conclusions}

Gli1 was upregulated in GA tissues and cancer cells and correlated with poor prognosis in GA patients. Knocking down Gli1 by specific inhibitor suppressed the expression of Gli1 protein levels. Reduced expression of Gli1 downregulated the protein levels of cancer stemness biomarkers while also decreasing cell clonogenic potential in GA cells. Thus, Gli1 may promote the progression of GA by maintaining GA cell stemness potential. Hh/Gli1 pathway may play an important role in CSC self-renewal and tumorigenicity. Taken the above results together, we speculated that Gli1 may play a potential role in cancer stemness and thus to accelerate the progression in GA.

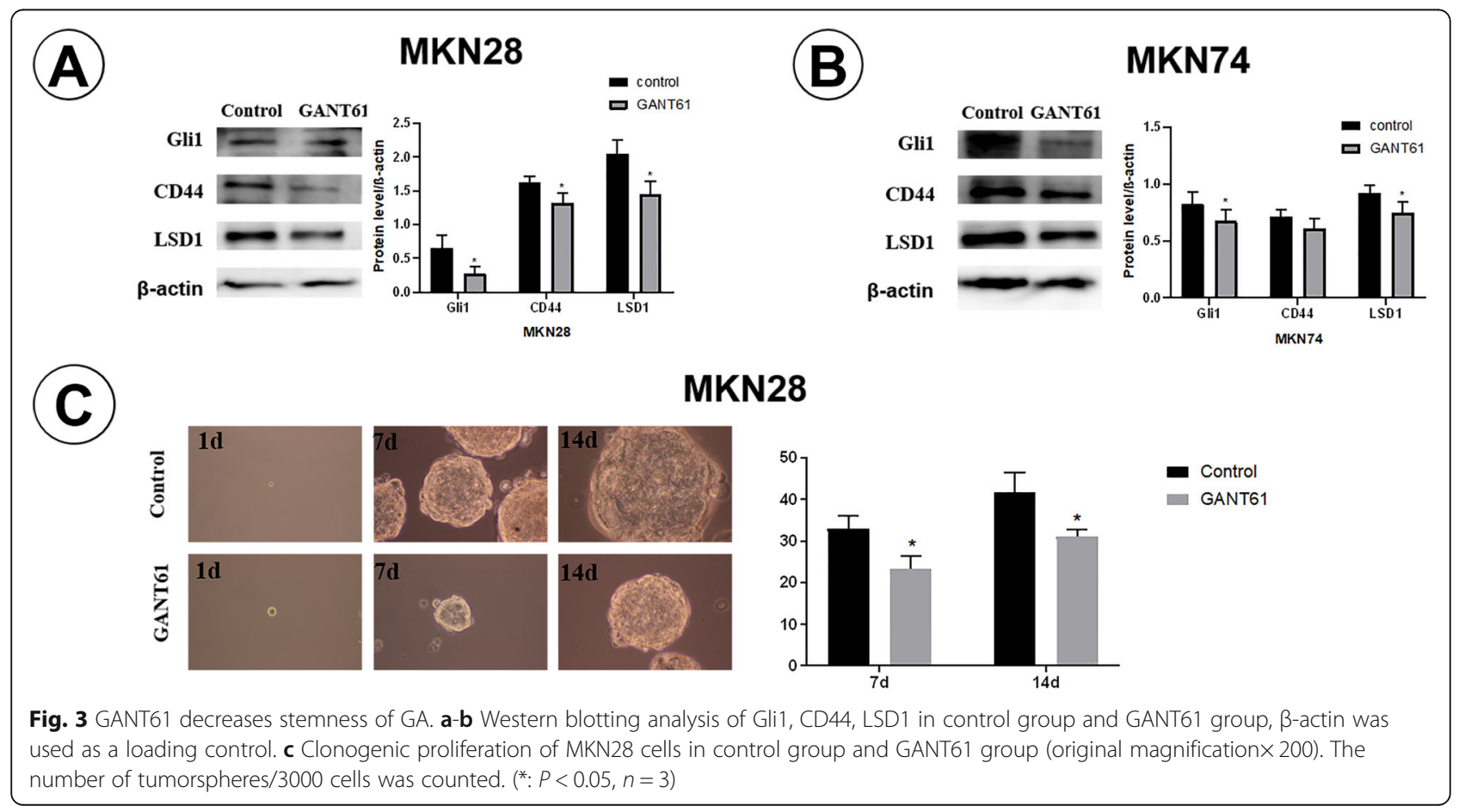




\section{Limitations of this current study}

Our study has several innate limitations to note. First, Spheroid formation experiments were performed only on the MKN28 cell line. Immunofluorescence was performed only on Gli1, LSD1, Sox9. Other stemness related features have not been tested.

\section{Supplementary information}

Supplementary information accompanies this paper at https://doi.org/10. 1186/s13000-020-00949-5.

Additional file 1: Supplemental Figure. The association between Gli1 mRNA expression and clinical stage, lymph node metastasis in GEPIA and TCGA data in GA.

\section{Abbreviations}

GA: Gastric adenocarcinoma; OS: Overall survival; CSCs: Cancer stem-like cells; Hh: Hedgehog; Ptc: Patched; Smo: Smoothened; Gli: Glioma-associated oncogene; PT: primary tumor; IHC: Immunohistochemical; PMSF: Phenyl methane sulfonyl fluoride; TMA: Tissue Microarray

\section{Acknowledgments}

We would like to thank Editage (www.editage.cn) for English language editing.

\section{Authors' contributions}

Yanhua Xuan collected surgical material, designed the study, and performed the statistical analysis. Wenbo Qi performed immunohistochemical staining, Western blotting, Immunofluorescence analysis, Tumorsphere-forming assay, interpreted the results, and drafted the manuscript. Zhaoting Yang and Ying Feng, Haoyue Li, Nan Che, Lan Liu, and Yanhua Xuan reviewed the literature the manuscript. All authors read and approved the final manuscript.

\section{Funding}

National Natural Science Foundation of China $(81760531,31760330$

31860321) approved this study.

\section{Availability of data and materials}

All data generated or analyzed during this study are included in this published article.

\section{Ethics approval and consent to participate}

This research complied with the Helsinki Declaration and was approved by the Human Ethics Committee and the Research Ethics Committee of Yanbian University Medical College in China. All patients provided written informed consent according to institutional guidelines. Patients were informed that the resected specimens were stored by the hospital and might potentially be used for scientific research, and that their privacy would be maintained. Follow-up survival data were collected retrospectively through medical-record analyses.

\section{Consent for publication}

Not applicable.

\section{Competing interests}

The authors declare that they have no competing interests.

\section{Author details}

${ }^{1}$ Institute for Regenerative Medicine, Yanbian University College of Medicine, Yanji, China. ${ }^{2}$ Department of Surgical Oncology, Lanzhou University Second Hospital, Lanzhou 730000, China. ${ }^{3}$ Department of Pathology, Yanbian University College of Medicine, Yanji, China. ${ }^{4}$ Department of Pathology, Affiliated Hospital of Yanbian University, Yanji, China.
Received: 20 November 2019 Accepted: 19 March 2020

Published online: 19 May 2020

\section{References}

1. Zhang Q, Chen ZY, Chen CD, Liu T, Tang XW, Ren YT, et al. Training in early gastric cancer diagnosis improves the detection rate of early gastric cancer: an observational study in China. Medicine. 2015:94:0000000000000384.

2. Du L, Wang H, He L, Zhang J, Ni B, Wang $X$, et al. CD44 is of functional importance for colorectal cancer stem cells. Clin Cancer Res. 2008; 14:6751-60.

3. Guo J, Gao J, Li Z, Gong Y, Man X, Jin J, et al. Adenovirus vector-mediated Gli1 siRNA induces growth inhibition and apoptosis in human pancreatic cancer with Smo-dependent or Smo-independent Hh pathway activation in vitro and in vivo. Cancer Lett. 2013;339:185-94.

4. Sheng W, Dong M, Zhou J, Li X, Liu Q, Dong Q, et al. The clinicopathological significance and relationship of Gli1, MDM2 and p53 expression in resectable pancreatic cancer. Histopathology. 2014;64:523-35.

5. Rossi M, Magnoni L, Miracco C, Mori E, Tosi P, Pirtoli L, et al. $\beta$-Catenin and Gli1 are prognostic markers in glioblastoma. Cancer Biol Ther. 2011; 11:753-61.

6. Xu L, Kwon YJ, Frolova N, Steg AD, Yuan K, Johnson MR, et al. Gli1 promotes cell survival and is predictive of a poor outcome in ERa-negative breast cancer. Breast Cancer Res Treat. 2010;123:59-71.

7. Ni W, Yang Z, Qi W, Cui C, Cui Y, Xuan Y. Gli1 is a potential stem cell marker and predicts poor prognosis in ductal breast carcinoma. Hum Pathol. 2017; 69:38-45.

8. Cui Y, Cui CA, Yang ZT, Ni WD, Jin Y, Xuan YH. Gli1 expression in cancer stem-like cells predicts poor prognosis in patients with lung squamous cell carcinoma. Exp Mol Pathol. 2017;102:347-53.

9. $\quad$ Yang $Z T$, Yeo SY, Yin YX, Lin ZH, Lee HM, Xuan YH, et al. Tenascin-C, a prognostic determinant of esophageal squamous cell carcinoma. PLoS One. 2016;11:e0145807-23.

10. Nagai S, Nakamura M, Yanai K, Wada J, Akiyoshi T, Nakashima H, et al. Gli1 contributes to the invasiveness of pancreatic cancer through matrix metalloproteinase-9 activation. Cancer Sci. 2008;99(7):1377-84.

11. Karhadkar SS, Bova GS, Abdallah N, Dhara S, Gardner D, Maitra A, et al. Hedgehog signalling in prostate regeneration, neoplasia and metastasis. Nature. 2004;431(7009):707-12

12. Nolan-Stevaux O, Lau J, Truitt ML, Chu GC, Hebrok M, Fernández-Zapico ME, et al. GLI1 is regulated through smoothened-independent mechanisms in neoplastic pancreatic ducts and mediates PDAC cell survival and transformation. Genes Dev. 2009;23(1):24-36

13. Kubo M, Nakamura M, Tasaki A, Yamanaka N, Nakashima H, Nomura M, et al. Hedgehog signaling pathway is a new therapeutic target for patients with breast cancer. Cancer Res. 2004;64(17):6071-4.

14. Ten Haaf A, Bektas N, von Serenyi S, Losen I, Arweiler EC, Hartmann A, et al. Expression of the glioma-associated oncogene homolog (GLI) 1 in human breast cancer is associated with unfavourable overall survival. BMC Cancer. 2009;9:298.

15. Xu L, Kwon YJ, Frolova N, Steg AD, Yuan K, Johnson MR, et al. Gli1 promotes cell survival and is predictive of a poor outcome in ERalphanegative breast cancer. Breast Cancer Res Treat. 2010;123(1):59-71.

16. Folkman J. What is the evidence that tumors are angiogenesis dependent. $J$ Natl Cancer Inst. 1990:82(1):4-6.

17. Cui D, Chen X, Yin J, Wang W, Lou M, Gu S. Aberrant activation of hedgehog/Gli1 pathway on angiogenesis in gliomas. Neurol India. 2012;60: 589-96.

18. Yang Z, Cui Y, Ni W, Kim S, Xuan Y. Gli1, a potential regulator of esophageal cancer stem cell, is identifed as an independent adverse prognostic factor in esophageal squamous cell carcinoma. J Cancer Res Clin Oncol. 2017;143: 243-54

19. Clement V, Sanchez P, de Tribolet N, Radovanovic I, Ruiz i Altaba A. Hedgehog-GLI1 signaling regulates human glioma growth, cancer stem cell self-renewal, and tumorigenicity. Curr Biol. 2007;17:165-72.

20. Takaishi S, Okumura T, Tu S, Wang SS, Shibata W, Vigneshwaran R, et al. Identification of gastric cancer stem cells using the cell surface marker CD44. Stem Cells. 2009:27:1006-20.

21. Zhao P, Li Y, Lu Y. Aberrant expression of CD133 protein correlates with Ki67 expression and is a prognostic marker in gastric adenocarcinoma. BMC Cancer. 2010;10:218. 
22. Matsuoka J, Yashiro M, Sakurai K, Kubo N, Tanaka H, Muguruma K, et al. Role of the stemness factors sox2, oct3/4, and nanog in gastric carcinoma. J Surg Res. 2012;174:130-5.

23. Sashikawa Kimura M, Mutoh H, Sugano K. SOX9 is expressed in normal stomach, intestinal metaplasia, and gastric carcinoma in humans. J Gastroenterol. 2011;46:1292-9.

24. Barker N, Huch M, Kujala P, van de Wetering M, Snippert HJ, van Es JH, et al. Clevers $\mathrm{H}$ Lgr5(+ve) stem cells drive self-renewal in the stomach and build long-lived gastric units in vitro. Cell Stem Cell. 2010;6(1):25-36.

25. Simon E, Petke D, Böger C, Behrens HM, Warneke V, Ebert M, et al. The spatial distribution of LGR5+ cells correlates with gastric cancer progression. PLoS One. 2012;7:e35486.

26. Dalerba P, Dylla SJ, Park IK, Liu R, Wang X, Cho RW, et al. Phenotypic characterization of human colorectal cancer stem cells. Proc Natl Acad Sci U S A. 2007;104:10158-63.

27. Lee KM, Lee JS, Jung HS, et al. Late reactivation of sonic hedgehog by helicobacter pylori results in population of gastric epithelial cells that are resistant to apoptosis: implication for gastric carcinogenesis. Cancer Lett. 2010;287(1):44-53.

28. Pan S, Wu X, Jiang J, et al. Discovery of NVP-LDE225, a potent and selective smoothened antagonist. ACS Med Chem Lett. 2010;1:130-4.

29. Yoon C, Park DJ, Schmidt B, et al. CD44 expression denotes a subpopulation of gastric cancer cells in which hedgehog signaling promotes chemotherapy resistance. Clin Cancer Res. 2014;20(15):3974-88.

30. Dong $H$, Liu H, Zhou W, et al. GLI1 activation by non-classical pathway integrin avß3/ERK1/2 maintains stem cell-like phenotype of multicellular aggregates in gastric cancer peritoneal metastasis. Cell Death Dis. 2019; 10:574.

31. Ma ZB, Xu HY, Jiang $M$, et al. Arsenic trioxide induces apoptosis of human gastrointestinal cancer cells. World J Gastroenterol. 2014;20(18):5505-10.

\section{Publisher's Note}

Springer Nature remains neutral with regard to jurisdictional claims in published maps and institutional affiliations.

Ready to submit your research? Choose BMC and benefit from:

- fast, convenient online submission

- thorough peer review by experienced researchers in your field

- rapid publication on acceptance

- support for research data, including large and complex data types

- gold Open Access which fosters wider collaboration and increased citations

- maximum visibility for your research: over $100 \mathrm{M}$ website views per year

At $\mathrm{BMC}$, research is always in progress.

Learn more biomedcentral.com/submissions 